\title{
Clinicopathological and prognostic characteristics in patients with AFP-secreting gastric carcinoma
}

\author{
YAKUP BOZKAYA $^{1}$, NEBİ SERKAN DEMIRCI ${ }^{1}$, ALİCAN KURTIPEK $^{2}$, GÖKMEN UMUT ERDEM $^{1}$, \\ NURIYE YILDIRIM OZDEMIR ${ }^{1}$ and NURULLAH ZENGIN ${ }^{1}$
}

\author{
Departments of ${ }^{1}$ Medical Oncology, ${ }^{2}$ Internal Medicine, Ankara Numune Education and Research Hospital, Ankara, Turkey
}

Received December 12, 2016; Accepted May 16, 2017

DOI: $10.3892 / \operatorname{mco} .2017 .1288$

\begin{abstract}
The aim of the present study was to determine whether there are any clinicopathological or prognostic differences between patients with $\alpha$-fetoprotein-secreting gastric carcinoma (AFP-SGC) and non-AFP-SGC. Pathological parameters, clinical parameters, and treatment efficacy were compared in patients with AFP-SGC and non-AFP-SGC. In total, 362 patients (53 with AFP-SGC and 309 with nonAFP-SGC) were included in the present study. Patients with AFP-SGC had significantly higher levels of lymphovascular invasion, perineural invasion (PNI), rate of liver metastasis, and stage IV cancer compared with patients with non-AFPSGC $(\mathrm{P}<0.05)$. The median overall survival $(\mathrm{OS})$ rate was 12.6 months in the AFP-SGC group, and 22.1 months in the non-AFP-SGC group $(\mathrm{P}<0.001)$. The median OS and disease free survival (DFS) of patients with stage I-III AFP-SGC were 28.1 and 13.4 months, respectively, whereas for patients with non-AFP-SGC, the OS and DFS were 45.3 and 38.0 months, respectively $(\mathrm{P}=0.01 ; \mathrm{P}=0.02)$. The median $\mathrm{OS}$ for the stage IV AFP-SGC and non-AFP-SGC groups was 9.3 and 11.5 months, respectively $(\mathrm{P}=0.14)$. Multivariate analysis of the entire patient group revealed that the Eastern Cooperative Oncology Group (ECOG) performance score of $\geq 2$, lymph node involvement, presence of PNI, high levels of carcinoembryonic antigen, and distant metastasis were significantly correlated with OS. The lymph node involvement, ECOG performance score of $\geq 2$, AFP-SGC type, and weight loss at diagnosis were also significant factors influencing the DFS in the stage I-III group. In conclusion, patients with AFP-SGC had more aggressive clinicopathological features and biological behavior with an increased tendency of liver metastasis compared with patients with non-AFP-SGC. In the near future, AFP may become an important surrogate marker to manage therapies of patients with gastric cancer.
\end{abstract}

Correspondence to: Dr Yakup Bozkaya, Department of Medical Oncology, Ankara Numune Education and Research Hospital, Talatpasa Avenue, 06100 Ankara, Turkey

E-mail: dr_yakupbozkaya@hotmail.com

Key words: $\alpha$-fetoprotein, $\alpha$-fetoprotein-secreting gastric carcinoma, gastric cancer, liver metastasis

\section{Introduction}

$\alpha$-fetoprotein (AFP) is a glycoprotein synthesized from the fetal yolk sac and liver during the gestational period (1). In adults, a high level of AFP is considered abnormal, and a good tumor marker for monitoring or screening yolk sac tumors and hepatocellular carcinoma. Additionally, there is evidence that its level may be increased in solid tumors, including gastric carcinoma $(2,3)$.

In 1970, Bourreille et al (4) reported a case of gastric carcinoma with a high AFP level and synchronic liver metastasis for the first time. Thereafter, various studies have emphasized that patients with AFP-secreting gastric carcinoma (AFP-SGC) have a high incidence of liver metastasis, increased lymphovascular invasion (LVI), advanced stage cancer and poor prognosis (5-7). Furthermore, a previous study demonstrated that AFP-SGC has a higher proliferation index, lower apoptosis and richer neovascularization compared with non-AFP-SGC (8). These data gave rise to the consdieration that AFP-SGC is a special subtype of gastric carcinoma with a high malignant potential. However, few studies have been reported that assess the clinicopathological features and prognostic importance of this special subtype. The majority of them included non-metastatic patients who were given curative surgery (5). Therefore, the aim of the present study was to evaluate and compare the clinicopathological characteristics, treatment and prognostic features of patients with AFP-SGC and non-AFP-SGC independently of the disease stage (non-metastatic or metastatic).

\section{Patients and methods}

Between 2009 and 2015, the health records of 1,328 patients who were given a histopathological diagnosis of gastric cancer in our hospital (the Ankara Numune Education and Reearch Hospital, Ankara, Turkey) were investigated retrospectively. Of those, the medical data of 404 patients whose AFP levels were measured at the time of diagnosis were evaluated. The AFP cut-off value was defined as $9 \mathrm{ng} / \mathrm{ml}$ (normal range, 0-9 ng/ml), as determined from a UniCel Dxl 600-800 assay system (Beckman Coulter, Inc., Brea, CA, USA) in our laboratory. The patients that had an AFP level $>9 \mathrm{ng} / \mathrm{ml}$ at the time of diagnosis were defined as 'AFP-SGC' patients, and those with an AFP level $<9 \mathrm{ng} / \mathrm{ml}$ were categorized as 'non-AFP-SGC' patients, accordingly. A total of 13 patients 
who had diseases that may have caused high levels of AFP, including chronic liver diseases, cirrhosis, yolk sac tumor, teratoma and hepatocellular carcinoma, were excluded from the study. The analysis also excluded 29 patients who did not follow-up.

The patients with AFP-SGC and non-AFP-SGC were evaluated comparatively in terms of pathological parameters, such as LVI, perineural invasion (PNI), the disease stage, and tumor size; clinical parameters, such as age, weight loss at the time of diagnosis, smoking history, and performance status; and treatment modalities, such as curative surgery, adjuvant chemotherapy and radiotherapy, no surgery, and palliative chemotherapy.

To evaluate the performance status, the Eastern Cooperative Oncology Group (ECOG) performance scale was used; for the staging and node status, the American Joint Committee on Cancer staging system was used (9). The staging in patients who underwent surgery was performed via a histopathological examination, whereas, for metastatic patients who did not undergo surgery, clinical staging was used. Additionally, endoscopic and histopathological findings were recorded according to the Borrmann and Lauren histological classification systems, respectively (10).

The health status of the patients was determined by accessing the health records of the patients at the hospital and the registrations in the Central Population Administration System of the Turkish Republic.

Statistical analysis. The computer programme 'Statistical Package for the Social Sciences', version 18.0 for Windows (SPSS, Inc., Chicago, IL, USA) was used for the statistical analysis. The variables were investigated according to visual (histograms, probability plots) and analytical (Kolmogorov Simirnov/Shapiro-Wilk's test) methods to determine whether they were normally distributed or not. Non-parametric variables are presented as the median and range, and categorical variables are presented as the frequency with percentages. Continuous variables were analyzed using the Mann-Whitney U test. Categorical variables were analyzed using the Chi-square or Fisher exact test. Survival analysis was performed according to the Kaplan-Meier method, whereas log-rank statistics was used to compare the subgroups. The possible factors identified with univariate analyses were further entered into the Cox regression analysis, with backward selection, to determine independent predictors of survival. Overall survival (OS) was defined as the interval between diagnosis and death or date last known alive, whereas the duration between the end of primary treatment and recurrence was defined as the disease-free survival (DFS) rate. $\mathrm{P}<0.05$ was considered to indicate a statistically significant value.

\section{Results}

Clinicopathological parameters. A total of 362 patients were included in the present study. Of those 362 patients, 53 had AFP-SGC and 309 had non-AFP-SGC. Clinicopathological features of the patients are shown in Table I. The median age of all patients was 58 (range, 22-88), and $73.8 \%$ of them were male; $26.2 \%$ were female.

Although no significant differences were identified in terms of the clinical and pathological parameters of age, sex,
Table I. Demographic characteristics of the patients.

\begin{tabular}{|c|c|c|c|}
\hline Characteristics & $\begin{array}{l}\text { AFP-SGC } \\
(\%)(n=53)\end{array}$ & $\begin{array}{l}\text { Non-AFP-SGC } \\
(\%)(n=309)\end{array}$ & $\mathrm{P}$-value \\
\hline Age (median, range) & $58(22-87)$ & $59(23-88)$ & 0.72 \\
\hline \multicolumn{4}{|l|}{ Sex } \\
\hline Female & $13(24.5)$ & $82(26.5)$ & 0.75 \\
\hline Male & $40(75.5)$ & $227(73.5)$ & \\
\hline Smoking & $35(66.0)$ & $193(62.5)$ & 0.61 \\
\hline \multicolumn{4}{|l|}{ ECOG } \\
\hline $0-1$ & $33(62.3)$ & 243 (78.6) & 0.01 \\
\hline $2-4$ & $20(37.7)$ & $66(21.4)$ & \\
\hline Weight loss & $20(37.7)$ & $139(45.0)$ & 0.32 \\
\hline Comorbidity & $23(43.4)$ & $139(45)$ & 0.83 \\
\hline \multicolumn{4}{|l|}{ Lauren classification } \\
\hline Intestinal & $15(34.9)$ & 107 (37) & 0.59 \\
\hline Diffuse & $16(37.2)$ & $121(41.9)$ & \\
\hline Mixed & $12(27.9)$ & $61(21.1)$ & \\
\hline Depth of invasion & & & 0.88 \\
\hline $\mathrm{T} 1+\mathrm{T} 2$ & $4(21.1)$ & $42(19.7)$ & \\
\hline $\mathrm{T} 3+\mathrm{T} 4$ & $15(78.9)$ & $171(80.3)$ & \\
\hline $\begin{array}{l}\text { Tumor size, cm } \\
\text { (median, range) }\end{array}$ & $4(1-13)$ & $4(4-17)$ & 0.78 \\
\hline TNM stage & & & $<0.001$ \\
\hline $1-2$ & $5(9.4)$ & $83(26.9)$ & \\
\hline 3 & $10(18.9)$ & $93(30.1)$ & \\
\hline 4 & $38(71.7)$ & $133(43.0)$ & \\
\hline Borrmann type & & & 0.37 \\
\hline $\mathrm{I}+\mathrm{II}$ & $8(15.1)$ & $63(20.4)$ & \\
\hline III + IV & $45(84.9)$ & 246 (79.6) & \\
\hline Tumor location & & & 0.89 \\
\hline $\begin{array}{l}\text { Fundus cardia } \\
\text { diffuse }\end{array}$ & $21(39.6)$ & $114(36.9)$ & \\
\hline Corpus & $17(32.1)$ & $98(31.7)$ & \\
\hline Antrum & $15(28.3)$ & $97(31.4)$ & \\
\hline LVI & $27(77.1)$ & $156(60.2)$ & 0.05 \\
\hline PNI & $26(74.3)$ & 145 (56.2) & 0.04 \\
\hline $\begin{array}{l}\text { Location of } \\
\text { metastases at } \\
\text { diagnosis }\end{array}$ & 38 & 133 & \\
\hline Liver & $31(81.6)$ & $61(45.9)$ & $<0.001$ \\
\hline Peritoneum & $6(15.8)$ & $46(34.6)$ & 0.02 \\
\hline $\begin{array}{l}\text { Intra-abdominal } \\
\text { distant LAP }\end{array}$ & $11(28.9)$ & $47(35.3)$ & 0.46 \\
\hline Lung & $6(15.8)$ & $14(10.5)$ & 0.39 \\
\hline Bone & $5(13.2)$ & $12(9)$ & 0.53 \\
\hline Others & $6(15.8)$ & $38(28.6)$ & 0.11 \\
\hline
\end{tabular}

Statistically significant $\mathrm{P}$-values $(\mathrm{P}<0.05)$ are shown in bold. AFP-SGC, $\alpha$-fetoprotein-secreting gastric cancer; ECOG, Eastern Cooperative Oncology Group; LAP, lymphadenopathy; LVI, lymphovascular invasion; non-AFP-SGC, non- $\alpha$-fetoprotein-secreting gastric cancer; PNI, perineural invasion; TNM, tumor-lymph nodemetastasis. 
smoking history, comorbidities, Lauren classification, tumor size, Borrmann type or tumor localization between the patients with AFP-SGC and non-AFP-SGC, the presence of LVI or PNI, an ECOG performance score of $\geq 2$, stage IV disease [according to the tumor-lymph node-metastasis (TNM) staging system], and liver metastasis were significantly more frequent in the AFP-SGC group $(\mathrm{P}<0.05)$. The non-AFP-SGC group had more frequent peritoneal metastasis $(\mathrm{P}<0.05)$ (Table I).

Comparing the laboratory analyses between the two groups, no statistically significant differences were identified in the levels of lactate dehydrogenase, hemoglobin and albumin; however, high levels of carcinoembryonic antigen (CEA) were present more frequently in the AFP-SGC group (64.2 vs. $28.5 \%$; $\mathrm{P}<0.001)$.

OS analysis in the whole patient group. Median follow-up durations for the patients with AFP-SGC or non-AFP-SGC were 11.7 (range, 1.0-54.2) and 15.6 (range, 0.4-83.0) months, respectively. The median OS was 12.6 months (range, 6.1-19.1) in the AFP-SGC group, and 22.1 months (range, 19.0-25.2) in the non-AFP-SGC group $(\mathrm{P}<0.001)$ (Fig. 1), whereas the 1- and 2-year survival rates were 55 and $25 \%$, respectively, in the AFP-SGC group; they were 73 and 47\%, respectively, in the non-AFP-SGC group $(\mathrm{P}<0.001)$.

The median survival in the whole group was 20.9 months [95\% confidence interval (CI), 18.3-23.4]. Prognostic factors affecting the OS were evaluated using the long-rank test. An ECOG performance score of $\geq 2(\mathrm{P}<0.001)$, weight loss at time of diagnosis $(\mathrm{P}<0.001)$, AFP-SGC type $(\mathrm{P}<0.001)$, presence of PNI $(\mathrm{P}<0.001)$, presence of LVI $(\mathrm{P}=0.02)$, high levels of CEA at the time of diagnosis $(\mathrm{P}<0.001)$, metastatic disease at the time of diagnosis $(\mathrm{P}<0.001)$, and lymph node positivity $(\mathrm{P}=0.06)$ were the factors that influenced the OS. In the multivariate analyis, an ECOG performance score of $\geq 2$, lymph node positivity, the presence of PNI, high levels of CEA, and metastatic disease at the time of diagnosis were identified to be independent prognostic factors (Table II).

Survival data in the stage I-III patient group. The OS and DFS data of 191 patients were at stages I-III at the time of diagnosis, and who had curative surgery, were evaluated. Of those patients, 15 of them (7.8\%) were in the AFP-SGC group, and 176 patients $(92.2 \%)$ were in the non-SFP-SGC group. A total of $28.3 \%$ of the AFP-SGC patients $(n=15)$ and $57 \%$ of the non-AFP-SGC patients $(n=176)$ underwent curative surgery $(\mathrm{P}<0.001)$. Metastatic or recurrent disease occurred in $60 \%(n=9)$ of the 15 AFP-SGC patients, and the liver was the most common site of metastasis $(66.7 \%)$. In the non-AFP-SGC group, metastatic or recurrent disease occurred in $42 \%(n=74)$ of the 176 patients, and the most common site of metastasis was the peritoneum $(22.9 \%, n=17)$. No differences were identified in the proportions of patients taking adjuvant treatment, comparing between the AFP-SGC and non-AFP-SGC groups $(66.7 \%$ vs. $73.3 \%$; $\mathrm{P}=0.55)$. The DFS of patients with stage I-III AFP-SGC or non-AFP-SGC was 13.4 (95\% CI, 10.9-15.9) and 38.0 (95\% CI, 23.2-52.9) months, respectively $(\mathrm{P}=0.01)$ (Fig. 2). Additionally, the median OS of patients with stage I-III AFP-SGC was 28.1 months (95\% CI, 13.3-42.9), whereas, for non-AFP-SGC patients, it was 45.3 months $(95 \%$ CI, 38.7-51.8; $\mathrm{P}=0.02$ ) (Fig. 3).

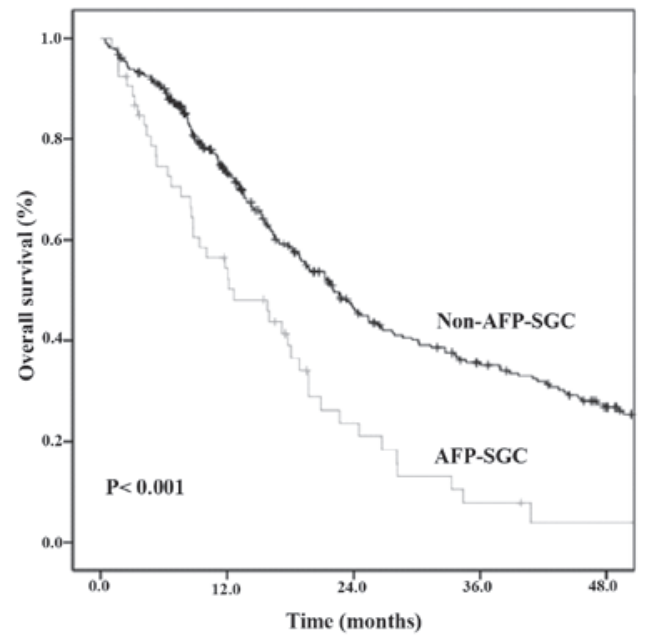

Figure 1. Univariate analysis curves for overall survival of patients with AFP-SGC or non-AFP-SGC. AFP-SGC, $\alpha$-fetoprotein-secreting gastric cancer; non-AFP-SGC, non- $\alpha$-fetoprotein-secreting gastric cancer.

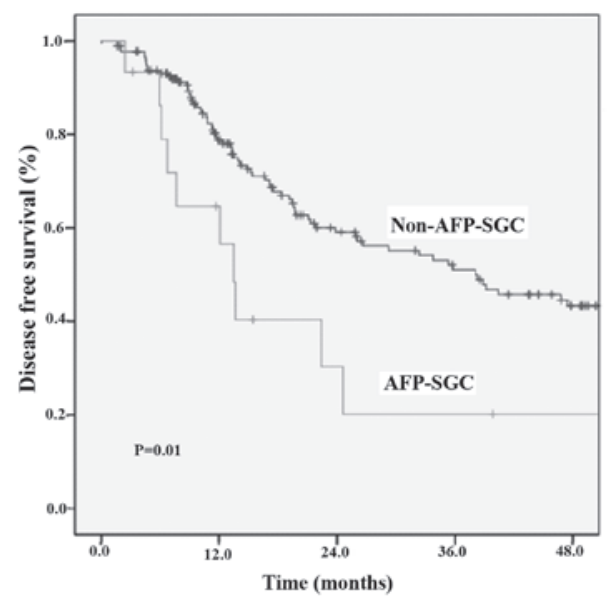

Figure 2. Univariate analysis curves for disease free survival of patients with stage I-III AFP-SGC or non-AFP-SGC. AFP-SGC, $\alpha$-fetoprotein-secreting gastric cancer; non-AFP-SGC, non- $\alpha$-fetoprotein-secreting gastric cancer.

Univariate and multivariate analyses were performed with respect to the factors affecting the DFS. The AFP-SGC type $(\mathrm{P}=0.01)$, an ECOG performance score of $\geq 2(\mathrm{P}=0.02)$, the presence of PNI $(\mathrm{P}=0.03)$, lymph node positivity $(\mathrm{P}<0.001)$ and weight loss at the time of diagnosis $(\mathrm{P}=0.03)$ were significant parameters for DFS in the univariate analysis. For the multivariate analysis, an ECOG performance score of $\geq 2$, lymph node positivity, AFP-SGC and weight loss at the time of diagnosis were independent prognostic factors (Table III).

In patients with stage I-III cancer, univariate analyse for OS demonstrated that an ECOG performance score of $\geq 2(\mathrm{P}=0.01)$, the AFP-SGC type $(\mathrm{P}=0.02)$, a tumor size of $\geq 5 \mathrm{~cm}(\mathrm{P}=0.008)$, lymph node positivity $(\mathrm{P}=0.004)$ and the presence of $\mathrm{PNI}(\mathrm{P}=0.003)$ were statistically significant. As for the multivariate analysis, an ECOG performance score of $\geq 2(\mathrm{P}=0.019)$ and lymph node positivity $(\mathrm{P}=0.039)$ were significant for the OS (Table III).

Survival data in the stage IV patient group. At the time of diagnosis, 171 patients $(47.2 \%)$ from the two groups presented 
Table II. Univariate and multivariate analysis of the clinicopathological characteristics of all the patients.

\begin{tabular}{|c|c|c|c|c|}
\hline Characteristic & No. of patients (\%) & Univariate analysis for OS & P-value (univariate) & Multivariate analysis \\
\hline Age (mean, years) & & & 0.34 & \\
\hline$<60$ & $186(51.4)$ & 21.9 & & \\
\hline$\geq 60$ & 176 (48.6) & 19.3 & & \\
\hline Sex & & & 0.59 & \\
\hline Female & $95(26.2)$ & 18.7 & & \\
\hline Male & $267(73.8)$ & 21.2 & & \\
\hline ECOG & & & $<0.001$ & $\mathbf{P}=\mathbf{0 . 0 0 3}, \mathrm{HR}=1.957$, \\
\hline $0-1$ & $276(76.2)$ & 23.9 & & $95 \% \mathrm{CI}=1.263-3.032$ \\
\hline $2-4$ & $86(23.8)$ & 10.0 & & \\
\hline Weight loss & & & $<0.001$ & $\mathrm{P}=0.309, \mathrm{HR}=1.230$, \\
\hline Yes & $159(43.9)$ & 15.9 & & $95 \% \mathrm{CI}=0.826-1.832$ \\
\hline No & $203(56.1)$ & 25.3 & & \\
\hline Tumor type & & & $<0.001$ & $\mathrm{P}=0.640, \mathrm{HR}=1.165$, \\
\hline AFP-SGC & $53(14.6)$ & 12.6 & & $95 \% \mathrm{CI}=0.614-2.211$ \\
\hline Non-AFP-SGC & $309(85.4)$ & 22.1 & & \\
\hline Comorbidity & & & 0.36 & \\
\hline Yes & $162(44.8)$ & 18.8 & & \\
\hline No & $200(55.2)$ & 22.7 & & \\
\hline Smoking & & & 0.76 & \\
\hline Yes & $228(63.0)$ & 22.0 & & \\
\hline No & $134(37.0)$ & 18.8 & & \\
\hline Tumor location & & & 0.08 & $\mathrm{P}=0.767, \mathrm{HR}=1.072$, \\
\hline Fundus cardia diffuse & $136(37.6)$ & 19.7 & & $95 \% \mathrm{CI}=0.678-1.694$ \\
\hline Corpus & $114(31.5)$ & 16.3 & & \\
\hline Antrum & $112(30.9)$ & 23.7 & & \\
\hline Tumor size (cm) & & & 0.75 & \\
\hline$<5$ & $226(62.4)$ & 18.7 & & \\
\hline$\geq 5$ & $136(37.6)$ & 23.8 & & \\
\hline Node & & & 0.06 & $\mathbf{P}=\mathbf{0 . 0 3 1}, \mathrm{HR}=1.746$, \\
\hline Positive & $169(70.1)$ & 26.5 & & $95 \% \mathrm{CI}=1.053-2.895$ \\
\hline Negative & $72(29.9)$ & 45.7 & & \\
\hline PNI & & & $<0.001$ & $\mathbf{P}=\mathbf{0 . 0 4 9}, \mathrm{HR}=1.579$ \\
\hline Yes & $171(58.3)$ & 22.6 & & $95 \% \mathrm{CI}=1.003-2.486$ \\
\hline No & $122(41.7)$ & 39.6 & & \\
\hline LVI & & & 0.02 & $\mathrm{P}=0.331, \mathrm{HR}=1.285$, \\
\hline Yes & $183(62.2)$ & 21.9 & & $95 \% \mathrm{CI}=0.775-2.132$ \\
\hline No & $111(37.8)$ & 28.6 & & \\
\hline Bormann type & & & 0.86 & \\
\hline I + II & $71(19.6)$ & 17.9 & & \\
\hline III + IV & 291(80.4) & 21.2 & & \\
\hline CEA (ng/ml) & & & $<0.001$ & $\mathbf{P}=\mathbf{0 . 0 1 8}, \mathrm{HR}=1.687$ \\
\hline$>5$ & $122(33.7)$ & 13.4 & & $95 \% \mathrm{CI}=1.093-2.604$ \\
\hline$\leq 5$ & $240(66.3)$ & 25.4 & & \\
\hline Metastases at diagnosis & & & $<0.001$ & $\mathrm{P}<0.001, \mathrm{HR}=2.323$ \\
\hline Yes & $171(47.2)$ & 11.4 & & $95 \% \mathrm{CI}=1.496-3.608$ \\
\hline No & $191(52.8)$ & 40.0 & & \\
\hline
\end{tabular}

Statistically significant P-values $(\mathrm{P}<0.05)$ are shown in bold. AFP-SGC, $\alpha$-fetoprotein-secreting gastric cancer, ECOG, Eastern Cooperative Oncology Group; LVI, lymphovascular invasion; non-AFP-SGC, non- $\alpha$-fetoprotein-secreting gastric cancer, PNI, perineural invasion; TNM, tumor-lymph node-metastasis; CEA, carcinoembryonic antigen; HR, hazard ratio; CI, confidence interval. 
Table III. Univarite and multivariate analysis of the clinicopathological characteristics of the patients with stage I-III cancer.

\begin{tabular}{|c|c|c|c|c|c|c|}
\hline Characteristic & $\begin{array}{c}\text { Univariate analysis } \\
\text { for OS }\end{array}$ & $\begin{array}{c}\text { P-value } \\
\text { (univariate) }\end{array}$ & $\begin{array}{l}\text { Multivariate analysis } \\
\text { for OS }\end{array}$ & $\begin{array}{c}\text { Univariate analysis } \\
\text { for DFS }\end{array}$ & $\begin{array}{c}\text { P-value } \\
\text { (univariate) }\end{array}$ & $\begin{array}{c}\text { Multivariate analysis } \\
\text { for DFS }\end{array}$ \\
\hline $\begin{array}{l}\text { Age } \\
\text { (mean, years) }\end{array}$ & & 0.63 & & & 0.75 & \\
\hline$<60$ & 47.1 & & & 38.0 & & \\
\hline$\geq 60$ & 40.8 & & & 26.0 & & \\
\hline Sex & & 0.67 & & & 0.24 & \\
\hline Female & 38.8 & & & 24.6 & & \\
\hline Male & 44.0 & & & 35.3 & & \\
\hline ECOG & & 0.01 & $\begin{array}{l}\mathbf{P}=\mathbf{0 . 0 1 9}, \mathrm{HR}=1.918, \\
95 \% \mathrm{CI}=1.112-3.306\end{array}$ & & 0.02 & $\begin{array}{l}\mathbf{P}=\mathbf{0 . 0 3 3}, \mathrm{HR}=1.838, \\
95 \% \mathrm{CI}=1.051-3.213\end{array}$ \\
\hline $0-1$ & 45.7 & & & 38.0 & & \\
\hline $2-4$ & 23.3 & & & 17.4 & & \\
\hline Weight loss & & 0.08 & $\begin{array}{l}\mathrm{P}=0.120, \mathrm{HR}=1.439 \\
95 \% \mathrm{CI}=0.910-2.276\end{array}$ & & & $\begin{array}{l}\mathrm{P}=0.028, \mathrm{HR}=1.656 \\
95 \% \mathrm{CI}=1.056-2.596\end{array}$ \\
\hline Yes & 26.5 & & & 17.4 & 0.03 & \\
\hline No & 47.1 & & & 38.8 & & \\
\hline Tumor type & & 0.02 & $\begin{array}{l}\mathrm{P}=0.307, \mathrm{HR}=1.492 \\
95 \% \mathrm{CI}=0.693-3.216\end{array}$ & & 0.01 & $\begin{array}{l}\mathbf{P}=\mathbf{0 . 0 2 1}, \mathrm{HR}=2.205, \\
95 \% \mathrm{CI}=1.087-4.473\end{array}$ \\
\hline AFP-SGC & 28.1 & & & 13.4 & & \\
\hline Non-AFP-SGC & 45.3 & & & 38.0 & & \\
\hline Tumor size $(\mathrm{cm})$ & & 0.008 & $\begin{array}{l}\mathrm{P}=0.066, \mathrm{HR}=1.856 \\
95 \% \mathrm{CI}=0.971-2.494\end{array}$ & & 0.13 & \\
\hline$<5$ & 67.6 & & & 39.1 & & \\
\hline$\geq 5$ & 32.6 & & & 24.6 & & \\
\hline Lymph node & & 0.004 & $\begin{array}{l}\mathbf{P}=\mathbf{0 . 0 3 9}, \mathrm{HR}=1.886, \\
95 \% \mathrm{CI}=1.031-3.449\end{array}$ & $<0.001$ & & $\begin{array}{l}\mathbf{P}<\mathbf{0 . 0 0 1}, \mathrm{HR}=4.156, \\
95 \% \mathrm{CI}=2.074-8.330\end{array}$ \\
\hline Positive & 32.6 & & & 24.4 & & \\
\hline Negative & N.R. ${ }^{a}$ & & & N.R. ${ }^{a}$ & & \\
\hline PNI & & 0.003 & $\begin{array}{l}\mathrm{P}=0.056, \mathrm{HR}=1.588 \\
95 \% \mathrm{CI}=0.988-2.552\end{array}$ & & 0.003 & $\begin{array}{l}\mathbf{P}=\mathbf{0 . 1 5 8}, \mathrm{HR}=1.401, \\
95 \% \mathrm{CI}=0.877-2.239\end{array}$ \\
\hline Yes & 30.2 & & & 21.0 & & \\
\hline No & 67.6 & & & 67.2 & & \\
\hline LVI & & 0.26 & & & 0.10 & \\
\hline Yes & 34.3 & & & 24.6 & & \\
\hline No & 47.8 & & & 47.4 & & \\
\hline Bormann type & & 0.92 & & & & \\
\hline $\mathrm{I}+\mathrm{II}$ & 43.4 & & & N.R.a & 0.14 & \\
\hline III + IV & 44.0 & & & 26.6 & & \\
\hline $\mathrm{CEA}(\mathrm{ng} / \mathrm{ml})$ & & 0.16 & & & 0.14 & \\
\hline$>5$ & 24.4 & & & 38.8 & & \\
\hline$\leq 5$ & 45.3 & & & 35.3 & & \\
\hline
\end{tabular}

${ }^{a}$ The median survival has not been reached (N.R.). Statistically significant P-values $(\mathrm{P}<0.05)$ are shown in bold. AFP-SGC, $\alpha$-fetoproteinsecreting gastric cancer; CEA, carcinoembryonic antigen; DFS, disease free survival; ECOG, Eastern Cooperative Oncology Group; LVI, lymphovascular invasion; non-AFP-SGC, non- $\alpha$-fetoprotein-secreting gastric cancer; OS, overall survival; PNI, perineural invasion.

with stage IV disease; of these, 38 (22.2\%) had AFP-SGC and $133(77.8 \%)$ had non-AFP-SGC. The most frequently implemented first-line chemotherapy regimen was modified docetaxel/cisplatin/5-flourouracil (DCF) for patients with either AFP-SGC or non-AFP-SGC (85 and 79.4\%, respectively).
No statistically significant differences were identified for the first- or second-line chemotherapy choice, comparing between the two groups $(\mathrm{P}=0.82$ and 0.72 , respectively). The treatment features of the patients who developed metastasis during diagnosis, or at a later stage, are shown in Table IV. 
Table IV. Treatment characteristics of the patients with AFP-SGC or non-AFP-SGC.

\begin{tabular}{lccc}
\hline & $\begin{array}{c}\text { AFP-SGC (\%) } \\
(\mathrm{n}=53)\end{array}$ & $\begin{array}{c}\text { Non-AFP-SGC (\%) } \\
(\mathrm{n}=309)\end{array}$ & P-value \\
Characteristic & & & $<\mathbf{0 0 1}$ \\
\hline Curative surgery & $15(28.3)$ & $176(57.0)$ & \\
Yes & $38(71.7)$ & $133(43.0)$ & 0.57 \\
No & & & \\
Lymphadenectomy & $3(15.8)$ & $48(23.6)$ & \\
D1 & $16(84.2)$ & $155(76.4)$ & 0.55 \\
D2 & $10(66.7)$ & $129(73.3)$ & 0.82 \\
Adjuvant CRT/RT & & & \\
First-line & & $135(79.4)$ & \\
chemotherapy & $34(85.0)$ & $20(11.8)$ & \\
DCF & $3(7.5)$ & $7(4.1)$ & \\
EOX & $1(2.5)$ & $8(4.7)$ & \\
FOLFOX & $2(5.0)$ & & \\
CFF & & & \\
Second-line & & $10(14.1)$ & \\
chemotherapy & $12(70.6)$ & $14(19.7)$ & \\
EOX & $3(17.6)$ & $2(11.8)$ & \\
FOLFIRI & & & \\
Capesitabine & & & \\
\hline
\end{tabular}

CFF, cisplatin/5-fluorouracil/folinic acid; CRT, chemoradiotherapy; DCF, docetaxel/cisplatin/5-fluorouracil; EOX, epirubicin/oxaliplatin/capecitabine; FUFA, 5-fluorouracil/folinic acid; FOLFIRI, 5-fluorouracil/folinic acid/irinotecan; RT, radiotherapy; AFP-SGC, $\alpha$-fetoprotein-secreting gastric cancer; non-AFP-SGC, non- $\alpha$-fetoprotein-secreting gastric cancer.

The OS analysis between the stage IV patients revealed that the median OS for the AFP-SGC group was 9.3 months (95\% CI, 4.8-13.8), and that of non-AFP-SGC group was 11.5 months (95\% CI, 9.4-13.6) (P=0.14) (Fig. 4).

\section{Discussion}

Serum AFP levels may not often be raised in various types of solid tumors, other than the well-known hepatocellular carcinoma and yolk sac tumors $(2,11-16)$. The most common of these is stomach adenocarcinoma (13). According to the literature, there are geographical differences associated with the incidence of AFP-SGC: It been reported most frequently in Western countries (up to 15\%), whereas in Middle Eastern countries, the incidence is $1.3-6.3 \%$ (7,17). In the current study, similar results were identified as for the Western countries, with a rate of $14.6 \%$. The wide range of incidence rates of AFP-SGC reported in the literuature, as for numerous other types of tumor, may be explained by differences in ethnicity, geographic localization and measurement techniques.

There are clinical and prognostic indicators that have a well-known prognostic value, including LVI, PNI, and the disease stage in gastric cancer (18-20). In the current study, these indicators were evaluated in the two groups, and patients with AFP-SGC were revealed to be diagnosed at more advanced stages, and to have more LVI and PNI compared with the non-AFP-SGC group. Similar findings were demonstrated in a study by Chang et al (7), who analyzed the data of 27 patients with AFP-SGC, and 478 with non-AFP-SGC. They

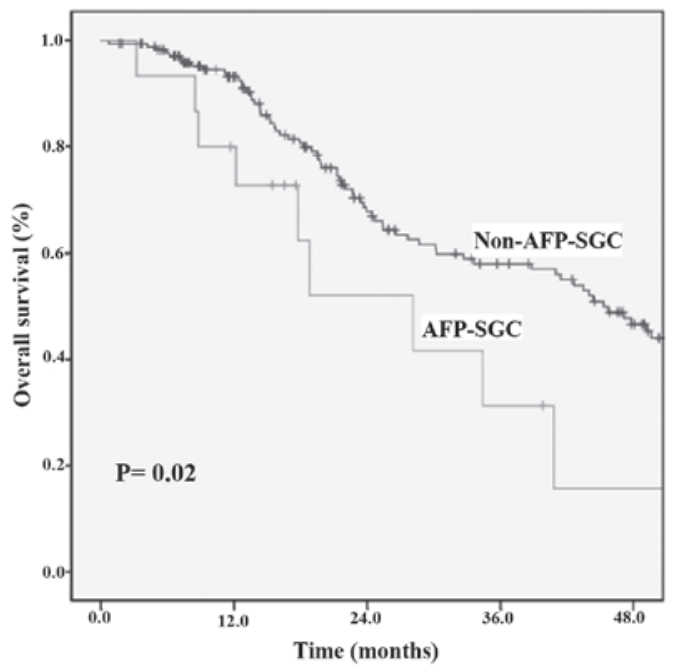

Figure 3. Univariate analysis curves for overall survival of patients with stage I-III AFP-SGC or non-AFP-SGC. AFP-SGC, $\alpha$-fetoprotein-secreting gastric cancer; non-AFP-SGC, non- $\alpha$-fetoprotein-secreting gastric cancer.

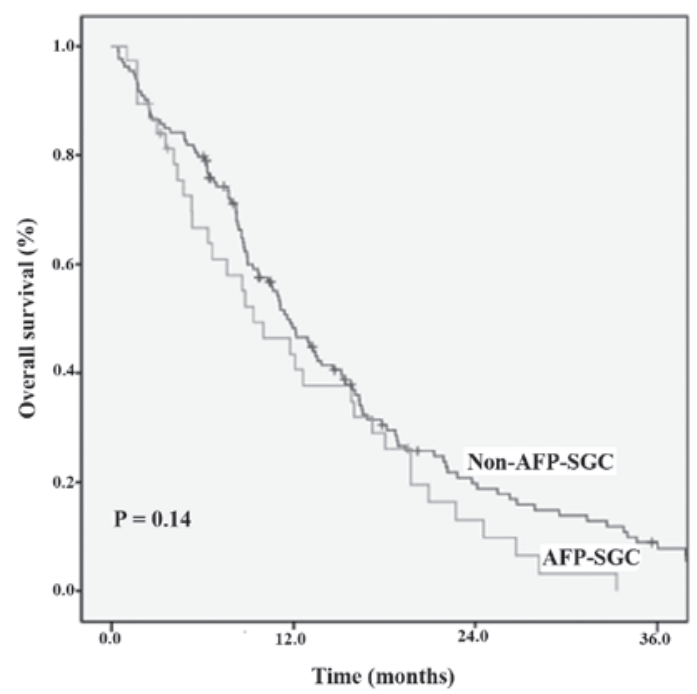

Figure 4. Univariate analysis curves for overall survival of patients with stage IV AFP-SGC or non-AFP-SGC. AFP-SGC, $\alpha$-fetoprotein-secreting gastric cancer; non-AFP-SGC, non- $\alpha$-fetoprotein-secreting gastric cancer.

identified that the AFP-secreting group had higher rates of LVI, PNI and advanced stage disease compared with the nonAFP-secreting group (7). Furthermore, Liu et al (21) reported that 104 patients with AFP-SGC had higher rates of vascular invasion and lymph node metastasis. Similar findings have supported that the AFP-SGC type exhibits a more aggressive behaviour, although the molecular mechanism of this aggressive behaviour has yet to be fully elucidated. Several studies have suggested that hepatocyte growth factor and c-Met receptor are important for cell proliferation and migration (22-25). Amemiya et al (26) demonstrated more frequent c-Met overexpression for the AFP-SGC group compared with the non-AFP-SGC group in a series of cases (26). Based on their results, they proposed that the aggressive behaviour of the AFP-SGC tumors may be associated with c-Met overexpression. However, further studies are necessary to elucidate the exact mechanism in this tumor group. 
Liver metastasis is one of the main features of AFP-SGC tumors, and the liver is the most common location for metastasis. In various studies, the rates of liver metastasis of the AFP-SGC patients have been reported to be between $14.3-75.6 \%$ (27-30). In the current study, patients with AFP-SGC had a higher rate of liver metastasis ( 81.6 vs. $45.9 \%$; $\mathrm{P}<0.001$ ), whereas patients with non-AFP-SGC had peritoneal metastasis more frequently ( 15.8 vs. $34.6 \%$; $\mathrm{P}=0.02$ ). The liver was also the most common site of metastases in patients with AFP-SGC who underwent curative surgery, whereas patients with non-AFP-SGC had the peritoneum as the most common site of metastasis. Similarly, Hirajima et al (31) also demonstrated that the AFP-SGC group had a higher liver metastasis rate, and the non-AFP-SGC group had a higher peritoneal metastasis rate (31). The data in the literature are generally consistent in reporting that AFP secretion is accompanied by a tendency towards liver metastasis. However, the underlying cause of this tendency of liver metastasis has yet to be fully elucidated.

Treatments based on 5-fluorouracil provide a standard therapy for gastric tumors, with respect to adjuvant or paliative strategies. However, in the available literature, data are lacking on the features and effectiveness of treatments for AFP-SGC. In the current study, the treatment choices were also evaluated, and in the two patient groups who received chemotherapy and chemoradiotherapy, the rates were similar. The first-line treatment choice was most commonly modified DCF chemotherapy for the two groups. No statistically significant differences were identified between the two groups in terms of first- or secondline chemotherapy choices. This was one of the important points that differentiated the current study from previous studies.

Long-term survival rates are low in patients with AFP-SGC, as they have the worse prognostic factors. Adachi et al (32) reported that 270 patients with stage I-IV AFP-SGC had a 5-year OS rate of 22\%, whereas Chang et al (33) reported a case series of AFP-SGC patients (stage I-IV) who had 1- and 3-year survival rates of 37.5 and $8.3 \%$, respectively. Wang et al (34) determined that 45 patients with AFP-SGC had 1,2, and 3-year survival rates that were lower than those of the AFP-negative group. The present study has also supported these data: The patients from all stages had 1- and 2-year survival rates of 55 and 25\% in the AFP-SGC group, respectively; whereas the non-AFP-SGC group had rates of 73 and $47 \%(\mathrm{P}<0.001)$. However, the prognostic value of AFP secretion was not significant in the multivariate analyses for all patient groups. When the patients were categorized in terms of their stages at diagnosis and analyzed seperately, it was revealed that AFP secretion was a prognostic factor for both DFS and OS in the non-metastatic patient group in the univariate analysis. In addition, AFP-SGC was shown to be an independent prognostic factor for DFS in the multivariate analysis. Findings reported previously in the literatüre, and those in the current study, indicated that AFP secretion is accompanied by a short OS. Apart from well-known prognostic parameters for gastric tumors, molecular classification studies are currently in progress that may lead to changes being effected in the course of the treatment (35). Under these circumstances, AFP might become a prognostic marker that could easily be applicable, with low costs.

There were several limitations of the current study. First, for patients with high levels of basal AFP, the AFP levels were not measured following the chemotherapy cycles to evaluate the response to chemotherapy. Secondly, the data were retrospectively evaluated from patients' files, and therefore the possibility of benign etiologies could not be eliminated, such as detailed mediation histories that may have led to the measurement of high levels of AFP.

In conclusion, AFP-SGC has the more aggressive clinicopathological features and biological behavior, with an increased tendency of liver metastasis. This tendency was revealed, with early recurrences, particularly in patients who underwent curative surgery. In the near future, by the increasing number of studies regarding this topic, AFP may become an important surrogate marker to manage therapies of patients with gastric cancer.

\section{References}

1. Bergstrand CG and Czar B: Demonstration of a new protein fraction in serum from the human fetus. Scand J Clin Lab Invest 8: 174-179, 1956.

2. Hamanaka W, Yoneda S, Shirakusa T, Shirahama H, Tashiro Y, Iwasaki A, Shiraishi T and Tsuru H: Alpha-fetoprotein (AFP)producing adrenocortical carcinoma--long survival with various therapeutic strategies including a lung resection: Report of a case. Surg Today 38: 275-278, 2008

3. Saito S, Hatano T, Hayakawa M, Koyama Y, Ohsawa A and Iwamasa T: Studies on alpha-fetoprotein produced by renal cell carcinoma. Cancer 63: 544-549, 1989.

4. Bourreille J, Metayer P, Sauger F, Matray F and Fondimare A: [Existence of alpha feto protein during gastric-origin secondary cancer of the liver]. Presse Med 78: 1277-1278, 1970.

5. Chang YC, Nagasue N, Abe S, Kohno H, Yamanoi A, Uchida M and Nakamura T: The characters of AFP-producing early gastric cancer. Nihon Geka Gakkai Zasshi 91: 1574-1580, 1990 (In Japanese)

6. Motoyama T, Aizawa K, Watanabe H, Fukase M and Saito K: alpha-Fetoprotein producing gastric carcinomas: A comparative study of three different subtypes. Acta Pathol Jpn 43: 654-661, 1993.

7. Chang YC, Nagasue N, Abe S, Taniura H, Kumar DD and Nakamura T: Comparison between the clinicopathologic features of AFP-positive and AFP-negative gastric cancers. Am J Gastroenterol 87: 321-325, 1992.

8. Koide N, Nishio A, Igarashi J, Kajikawa S, Adachi W and Amano J: Alpha-fetoprotein-producing gastric cancer: Histochemical analysis of cell proliferation, apoptosis, and angiogenesis. Am J Gastroenterol 94: 1658-1663, 1999.

9. Greene FL, Page DL and Fleming ID (eds): AJCC cancer staging manual. 6th edition. Springer, New York, 2002.

10. Laurén PA and Nevalainen TJ: Epidemiology of intestinal and diffuse types of gastric carcinoma. A time-trend study in Finland with comparison between studies from high- and low-risk areas. Cancer 71: 2926-2933, 1993.

11. Yamagata T, Yamagata Y, Nakanishi M, Matsunaga K, Minakata Y and Ichinose M: A case of primary lung cancer producing alphafetoprotein. Can Respir J 11: 504-506, 2004.

12. Matsueda K, Yamamoto $H$, Yoshida $Y$ and Notohara $K$ : Hepatoid carcinoma of the pancreas producing protein induced by vitamin $\mathrm{K}$ absence or antagonist II (PIVKA-II) and alphafetoprotein (AFP). J Gastroenterol 41: 1011-1019, 2006.

13. Kinjo T, Taniguchi H, Kushima R, Sekine S, Oda I, Saka M, Gotoda T, Kinjo F, Fujita J and Shimoda T: Histologic and immunohistochemical analyses of $\alpha$-fetoprotein--producing cancer of the stomach. Am J Surg Pathol 36: 56-65, 2012.

14. Cappetta A, Bergamo F, Mescoli C, Lonardi S, Rugge M and Zagonel V: Hepatoid adenocarcinoma of the colon: What should we target? Pathol Oncol Res 18: 93-96, 2012.

15. Kawamura N, Hatano K, Kakuta Y, Takada T, Hara T and Yamaguchi S: [A case of hepatoid adenocarcinoma of the urinary bladder]. Hinyokika Kiyo 55: 619-622, 2009.

16. Isonishi S, Ogura A, Kiyokawa T, Suzuki M, Kunito S, Hirama M, Tachibana T, Ochiai K and Tanaka T: Alpha-fetoprotein (AFP)producing ovarian tumor in an elderly woman. Int J Clin Oncol 14: 70-73, 2009. 
17. McIntire KR, Waldmann TA, Moertel CG and Go VL: Serum alpha-fetoprotein in patients with neoplasms of the gastrointestinal tract. Cancer Res 35: 991-996, 1975.

18. Deng J, You Q, Gao Y, Yu Q, Zhao P, Zheng Y, Fang W, Xu N and Teng L: Prognostic value of perineural invasion in gastric cancer: A systematic review and meta-analysis. PLoS One 9: e88907, 2014.

19. Dicken BJ, Graham K, Hamilton SM, Andrews S, Lai R, Listgarten J, Jhangri GS, Saunders LD, Damaraju S and Cass C: Lymphovascular invasion is associated with poor survival in gastric cancer: An application of gene-expression and tissue array techniques. Ann Surg 243: 64-73, 2006.

20. Talamonti MS, Kim SP, Yao KA, Wayne JD, Feinglass J, Bennett CL and Rao S: Surgical outcomes of patients with gastric carcinoma: The importance of primary tumor location and microvessel invasion. Surgery 134: 720-727, discussion 727-729, 2003.

21. Liu X, Cheng Y, Sheng W, Lu H, Xu Y, Long Z, Zhu H and Wang Y: Clinicopathologic features and prognostic factors in alpha-fetoprotein-producing gastric cancers: Analysis of 104 cases. J Surg Oncol 102: 249-255, 2010.

22. Matsumoto $\mathrm{K}$ and Nakamura T: Hepatocyte growth factor (HGF) as a tissue organizer for organogenesis and regeneration. Biochem Biophys Res Commun 239: 639-644, 1997.

23. Halaban R, Rubin JS, Funasaka Y, Cobb M, Boulton T, Faletto D, Rosen E, Chan A, Yoko K, White W, et al: Met and hepatocyte growth factor/scatter factor signal transduction in normal melanocytes and melanoma cells. Oncogene 7: 2195-2206, 1992.

24. Tajima H, Matsumoto $\mathrm{K}$ and Nakamura T: Regulation of cell growth and motility by hepatocyte growth factor and receptor expression in various cell species. Exp Cell Res 202: 423-431, 1992.

25. Matsumoto $\mathrm{K}$ and Nakamura T: Hepatocyte growth factor: Molecular structure, roles in liver regeneration, and other biological functions. Crit Rev Oncog 3: 27-54, 1992.

26. Amemiya H, Kono K, Mori Y, Takahashi A, Ichihara F, Iizuka H, Sekikawa T and Matsumoto Y: High frequency of c-Met expression in gastric cancers producing alpha- fetoprotein. Oncology 59: 145-151, 2000.
27. Zhang JF, Shi SS, Shao YF and Zhang HZ: Clinicopathological and prognostic features of hepatoid adenocarcinoma of the stomach. Chin Med J (Engl) 124: 1470-1476, 2011.

28. Chun $\mathrm{H}$ and Kwon SJ: Clinicopathological characteristics of alpha-fetoprotein-producing gastric cancer. J Gastric Cancer 11: 23-30, 2011.

29. Ucar E, Semerci E, Ustun H, Yetim T, Huzmeli C and Gullu M: Prognostic value of preoperative CEA, CA 19-9, CA 72-4, and AFP levels in gastric cancer. Adv Ther 25: 1075-1084, 2008.

30. Liu X, Cheng Y, Sheng W, Lu H, Xu X, Xu Y, Long Z, Zhu H and Wang Y: Analysis of clinicopathologic features and prognostic factors in hepatoid adenocarcinoma of the stomach. Am J Surg Pathol 34: 1465-1471, 2010.

31. Hirajima S, Komatsu S, Ichikawa D, Kubota T, Okamoto K, Shiozaki A, Fujiwara H, Konishi H, Ikoma $\mathrm{H}$ and Otsuji E: Liver metastasis is the only independent prognostic factor in AFP-producing gastric cancer. World J Gastroenterol 19: 6055-6061, 2013

32. Adachi Y, Tsuchihashi J, Shiraishi N, Yasuda K, Etoh T and Kitano S: AFP-producing gastric carcinoma: Multivariate analysis of prognostic factors in 270 patients. Oncology 65: 95-101, 2003.

33. Chang YC, Nagasue N, Kohno H, Taniura H, Uchida M, Yamanoi A, Kimoto T and Nakamura T: Clinicopathologic features and long-term results of alpha-fetoprotein-producing gastric cancer. Am J Gastroenterol 85: 1480-1485, 1990.

34. Wang D, Li C, Xu Y, Xing Y, Qu L, Guo Y, Zhang Y, Sun X and Suo J: Clinicopathological characteristics and prognosis of alpha-fetoprotein positive gastric cancer in Chinese patients. Int J Clin Exp Pathol 8: 6345-6355, 2015.

35. Chen T, Xu XY and Zhou PH: Emerging molecular classifications and therapeutic implications for gastric cancer. Chin J Cancer 35: 49, 2016. 